\title{
TECTÔNICA RÚPTIL DA REGIÃO ENTRE PILAR DO SUL E VOTORANTIM, SP.
}

\section{PAULO CÉSAR FERNANDES DA SILVA*}

\begin{abstract}
BRITTLE TECTONICS OF THE REGION BETWEEN PILAR DO SUL AND VOTORANTIM, SP. The western part of the Proterozoic São Roque Group, between the cities of Pilar do Sul and Votorantim (southeastern São Paulo State, Brazil), was mapped on a scale of 1:50.000. The study has focused upon structural analysis with main emphasis on brittle features. The following lithologic types outcrop in the study area: metassediments of the São Roque Group; metassediments correlated to Açungui and Serra do Itaberaba groups; varied granitic rocks (mainly correlated to the São Francisco, Sorocaba, Piedade and Pilar do Sul massifs); sediments of the Itararé Subgroup; Recent alluvionar deposits and minor ocurrence of alkaline and metabasic rocks.

Transcurrent shear zones are the main regional structural features and demarcate four structural domains. Within the context of brittle deformation, data sets for fault slip and joints reveal six well-defmed superposed stress fields at both local and regional scales, each corresponding to a specific time-interval of a distinct tectonic event. Following a first event of N-S compression, the five others - successively, NNW-SSE extension, NE-SW compression, NW-SE compression, WNW-ESE extension and E-W compression - are remarkably compatible with the currently accepted model for Cenozoic tectonic evolution of the eastern part of the State of São Paulo.
\end{abstract}

Keywords: brittle structures, principal directions of paleostress.

RESUMO 0 presente estudo foi realizado em escala $1: 50.000$, na região entre Pilar do Sul e Votorantim, porção centro-sudeste do Estado de São Paulo, e buscou a investigação de elementos estruturais com ênfase na caracterização de feições de natureza rúptil. Na referida área de estudo, ocorrem os seguintes litotipos: metassedimentos do Grupo São Roque, metassedimentos correlacionáveis ao Grupo Açungui e ao Grupo Serra do Itaberaba, rochas granitóides diversas (correlacionáveis, principalmente, aos Maciços de São Francisco, Sorocaba, Piedade e Pilar do Sul), sedi- mentos do Subgrupo Itararé, aluviões recentes e alguns litotipos de ocorrência restrita (rochas metabásicas e alcalinas). A análise teve lugar em quatro domínios estruturais delimitados por zonas de cisalhamento transcorrente, que se configuram em importantes feições regionais na área de estudo. A aplicação de método gráfico para determinação das direções principais de paleoesforços permitiu o reconhecimento de seis regimes de esforços ao longo da área de estudo, dois deles de características extensionais e quatro compressivos, provavelmente diacrônicos e, portanto, correspondendo a eventos de deformação distintos. O primeiro evento refere-se a esforços compressivos orientados segundo a direção N-S. Os demais eventos, sucessivamente extensão NNW-SSE, compressão NE-SW, compressão NW-SE, extensão WNW-ESE e compressão E-W, apresentam características compatíveis com os modelos de tectônica cenozóica sugeridos para a porção leste do estado de São Paulo.

Palavras-chave: estruturas rúpteis, direções principais de paleoesforços.

INTRODUÇÃO A área estudada compreende aproximadamente $400 \mathrm{~km}$, localizada na macrorregião administrativa de Sorocaba, entre as cidades de Pilar do Sul e Votorantim, porção centrosudeste do estado de São Paulo (Fig. 1).

$\mathrm{O}$ presente trabalho enfatiza as estruturas de natureza rúptil observadas na área em questão, e possivelmente vinculadas a uma história tectônica mais recente. Ó objetivo principal é o de apresentar um esboço dos regimes de esforços a que foram submetidas as rochas, a partir da análise de diferentes populações de dados estruturais (planos e estrias de falha) com aplicacão de métodos para determinacão gráfica das direções principais de esforços propostos em Angelier \& Mechler (1977) e Angelier (1994). Famílias de juntas com orientações sistemáticas e pervasivas ao longo da área também foram utilizadas para fins de correlação e de determinação de campos de paleoesforços, como sugerido por Hancock \& Engelder (1989), Dunne \& Hancock (1994) e Caputo(1995).

Estudos regionais de bacias tafrogênicas no Sudeste Brasileiro (Melo et al 1985, Riccomini et al. 1987, Riccomini et al. 1989) assinalaram que as deformações tectônicas ocorridas no período mesozóico-cenozóico corresponderiam a pelo menos duas fases distintas de desenvolvimento de esforços. Os modelos de evolução preconizados sugerem uma fase inicial distensiva, que teria início ao final do Mesozóico estendendo-se ao final do Terciário, seguida de regimes de esforços compressivos verificados principalmente em depósitos relativamente mais jovens, sugerindo idade posterior (Pleistoceno a Holoceno).

Riccomini (1989) propôs um quadro de evolução tectônica para o Rift Continental do Sudeste do Brasil definindo quatro fases de regimes de esforços distintos. Duas fases foram consideradas como pré-neotectônicas, a primeira de caráter extensional e a segunda transcorrente sinistrai. Duas outras fases, com campos de esforços distintos, foram consideradas como eventos neotectônicos: uma fase de transcorrência destral e, posteriormente, um evento extensional.

Na região do Baixo Vale do Rio Ribeira de Iguape (sudeste do estado de São Paulo), Melo (1990) caracterizou a atuação de esforços distensivos em torno das direções WNW - ESE e E-W, associando-os à ocorrência de falhas normais. $\mathrm{O}$ mesmo autor identificou falhas inversas e direcionais que truncam sedimentos cenozóicos (Formação Pariqüera-Açu e depósitos colúvio-aluviais) geradas e/ou reativadas por esforços compressivos na direção NE - SW.

Por meio de análise morfoestrutural combinada à caracterização dos depósitos sedimentares e das estruturas de caráter rúptil, Salvador (1994) e Salvador \& Riccomini (1995) reconheceram três fases de deformação neotectônicas na região do Vale do Rio Paraíba do Sul.
Essas movimentações estariam relacionadas inicialmente a esforços compressivos de idade pleistocênica, associados a um binário transcorrente destral de direção $\mathrm{E}$ - W. Os referidos autores preconizam uma mudança do regime de esforços durante o Holoceno, passando a extensionais com direções $\mathrm{E}-\mathrm{W}$ a WNW -ESE, registrando nova mudança para esforços compressivos de direção E-W.

Fernandes (1997), estudando a tectônica cenozóica na região de Campinas, porção média da Bacia do Rio Piracaba (centro-nordeste do estado de São Paulo), estabeleceu um modelo de evolução da tectônica rúptil constituído por cinco eventos de regime transcorrente, quatro deles afetando depósitos cenozóicos (Formação Rio Claro e correlates).

CONSIDERAÇÕES SOBRE A ÁREA DE ESTUDO Segundo o Mapa Geomorfológico Estado de São Paulo (IPT 1981), a área encontra-se no limite entre dois grandes domínios morfológicos: Planalto Atlântico e Depressão Periférica. No Domínio de Planalto, situase na interface entre as zonas do Planalto de Ibiúna e Serrania de São Roque, ocorrendo uma zona de transição com relevo de morrotes, declividades médias a altas, superiores a $15 \%$, e amplitudes locais inferiores a $100 \mathrm{~m}$. No Domínio da Depressão Periférica, abrange a Zona do Médio Tietê, onde predominam colinas amplas e médias na porção oeste da área, com declividades de até $15 \%$ e amplitudes inferiores a $100 \mathrm{~m}$. Na região de transição entre as duas províncias morfológicas (Planalto Atlântico e Zona do Médio Tietê, no domínio da Depressão Periférica), são registrados níveis de relevo que decrescem de altitude de forma gradual, no sentido do embasamento cristalino para a bacia sedimentar. Modenesi (1974) interpretou esses níveis como paleoformas resultantes de fases sucessivas de aplainamento lateral e dissecação vertical, sob condições de epirogênese lenta e gradual, correlacionando um dos níveis à Superficie Neogênica definida por Martonne (1943).

A região entre Votorantim e Pilar do Sul está compreendida, em grande parte, no domínio tectônico reconhecido como Bloco São Roque (Hasui et al. 1969), delimitado pelas zonas de cisalhamento transcorrente de Taxaquara, ao sul, e de Itu-Jundiuvira, ao norte. Outras zonas de cisalhamento subordinadas ou menores ocorrem no referido domínio, dentre as quais destacam-se a de Moreiras e a de Pirapora, orientadas segundo o trend regional (NE e ENE respectivamente) e que dividem a área estudada em subdomínios tectônicos. A porção situada ao sul da Zona de Cisalhamento Transcorrente de Taxaquara insere-se em um outro domínio tectônico, denominado Bloco Embu (Hasui et al. 1969). Trabalhos anteriores realizados na região e arredores descrevem rochas do embasa-mento cristalino constituído predominantemente por litotipos associados aos Grupos Serra do Itaberaba, Açun- 


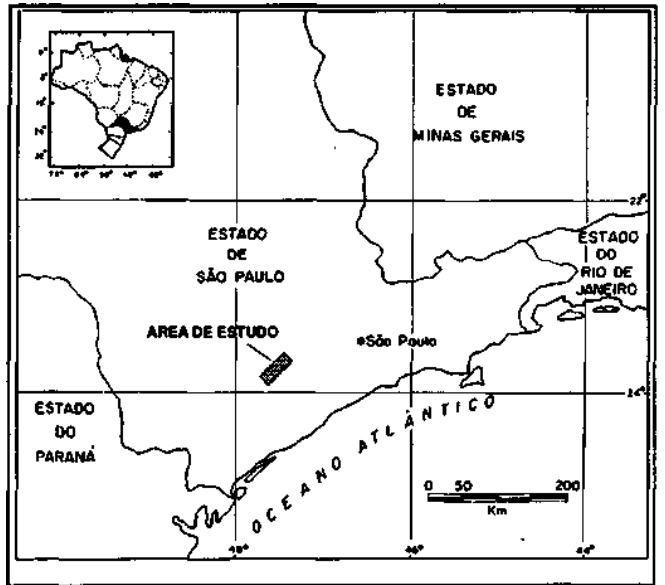

Figura l-Mapa de localização da área de estudo no estado de São Paulo.

gui e São Roque; além de rochas granitóides diversas e sedimentos do Subgrupo Itararé (Hasui 1973, 1975, Stein 1984, Juliani et al. 1986 , Bergmann 1988, Godoy 1989, IG/SMA 1990, Campos Neto et al. 1990, Godoy \& Figueiredo 1991, Massoli 1991, Pires \& Petri 1991, Oliveira et al. 1992, Pellogia \& Bergmann 1992, Hackspacher et al. 1993, Hackspacher 1994).

Fernandes da Silva (1997), através de mapeamento geológico sistemático realizado na escala 1: 50.000 , reconheceu os principais litotipos ocorrentes na área de estudo (Fig. 2). Ao norte, em Votorantim e arredores, predominam metassedimentos associados ao Grupo São Roque, que incluem metarritmitos, metargilitos maciços e laminados passando a metassiltitos bandados, metarenitos quartzosos e quartzofílitos intercalados a metadolomitos, metacalcilutitos e metacalcários Esta sequência é limitada a sudeste pela Zona de Cisalhamento de Moreiras, que representa contato brusco entre estes litotipos e rochas granitóides associadas ao Macico São Francisco. Na porção média da área de estudo, referente a Salto de Pirapora e arredores, afloram os sedimentos do Subgrupo Itararé (lamitos com seixos e siltitos, predominantemente maciços), rochas granitóides associados ao Maciço Sorocaba, e os litotipos associados ao Grupo São Roque, os quais apresentam sensíveis variações, tais como: metassiltitos laminados em contato interdigitado e transicional com metarritmitos e com filitos sericíticos; pequenos corpos de metarenitos feldspáticos a arcoseanos; metamargas laminadas a bandadas e biotita-clorita filitos bandados em associação com metacalcários, metacalcilutitos e metadolomitos, que neste trecho atingem termos calcareníticos. A Zona de Cisalhamento de Moreiras faz uma junção com a Zona de Cisalhamento de Pirapora que, por sua vez, delimita esta faixa de metassedimentos, assim como as rochas granitóides do Macico São Francisco ao sul.

$\mathrm{Na}$ porção mais ao sul (Pilar do Sul e arredores), ocorrem sedimentos de Subgrupo Itararé (ritmitos e arenitos principalmente) e litotipos associados ao Grupo Açungui (micaxistos e gnaisses), rochas granitóides associadas aos maciços Piedade e Pilar do Sul, e uma ocorrência local de rocha metabásica.

ANÁLISE DAS FEIÇÕES DE NATUREZA RÚPTIL Procedimentos $\mathrm{A}$ análise estrutural das feições de caráter rúptil foi efetuada com o intuito principal de caracterizar os regimes de esforços vigentes na geração das respectivas feições, procurando-se reconhecer a cronologia relativa dos eventos e campos de tensões associados. $\mathrm{O}$ estabelecimento dessa cronologia relativa tem por base a superposição de estrias sobre um mesmo plano de falha, relações de corte e deslocamento entre estruturas geradas por um mesmo regime ou por diferentes regimes de esforços, e relações geométricas e angulares entre as diferentes famílias de estruturas (sistemas de juntas, especialmente). Os dados coletados em campo correspondem aos litotipos do embasamento cristalino (metassedimentos do Grupo São Roque e rochas granitóides do Maciço São Francisco, em grande parte) e do Subgrupo Itararé (mais frequentemente lamitos e siltitos maciços). Os trabalhos de gabinete envolveram a aplicação de método para determinação gráfica das direções principais de esforços e procedimentos afins, em populações de dados referentes a planos de falhas e respectivas estrias de atrito. As famílias de juntas também foram utilizadas para a determinação de campos de esforços, sendo para tanto empregados dados

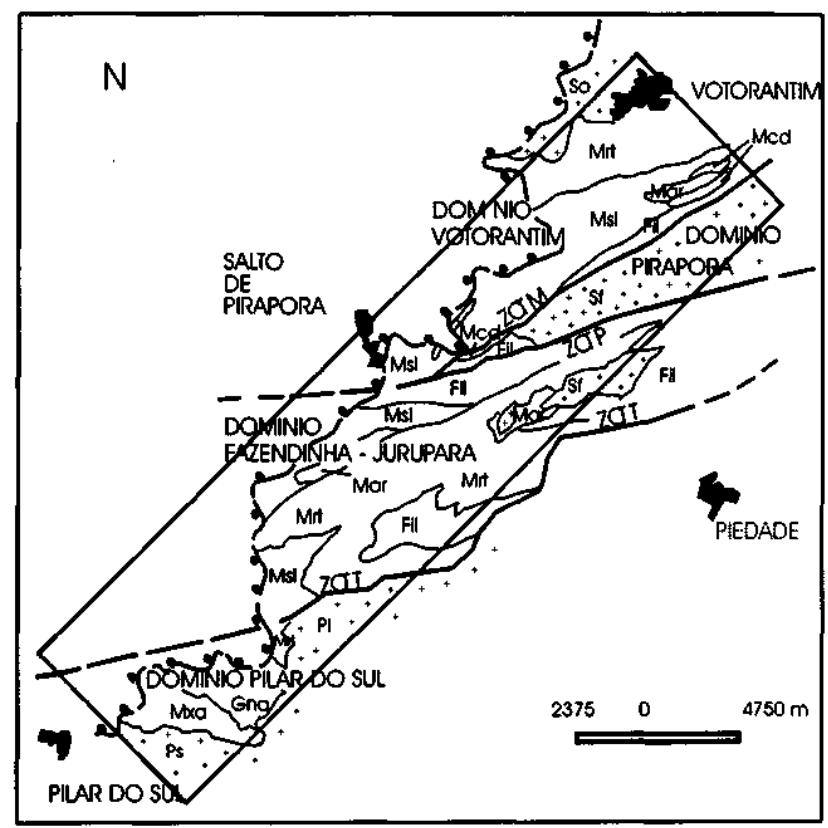

Figura 2 - Mapa geológico simplicado da área estudada (adaptado de Fernandes da Silva 1997) apresentando alguns dos principais litotipos e compartimentação em domínios estruturais delimitados por zonas de cisalhamento (ZCTM -Zona de Cisalhamento Transcorrente de Moreiras, ZCTP - Zona de Cisalhamento Transcorrente de Pirapora, ZCTT - Zona de Cisalhamento Transcorrente de Taxaquara). A linha tracejada acompanhada por pontos configura o limite aproximado da Bacia do Paraná (rochas sedimentares do Subgrupo Itararé). Litotipos associados ao Grupo São Roque: Mrt -metarritmitos; Msl metassiltitos e metargilitos; Mar -metarenitos quartzosos efeldspáticos; Mcd - metacarbonatos diversos; Fil - filitos diversos. Litotipos associados ao Grupo Açungui: Mxa - micaxistos; Gna - gnaisses félsicos passando a migmatitos. Litotipos granitóides: Só - Maciço Sorocaba; Sf - Maciço São Francisco; Pi - Maciço Piedade; Ps Maciço Pilar do Sul.

referentes aos sistemas de juntas que apresentaram comportamento pervasivo e direções sistemáticas ao longo da área de estudo.

Os dados foram inicialmente tratados e agrupados por afloramento ou por grupo de afloramentos muito próximos ou contíguos (pedreiras e locais de lavra para exploração mineral). Os atributos utilizados para a sistematização e controle de qualidade dos dados coletados em campo foram: 1) o tipo de estrutura (planos e estrias de falha, famílias de juntas, conjugados referentes a cada tipo); 2) sentido de movimento (sinistrai, destral, normal e inverso); 3) dimensões (mm, cm, dm, m, $\mathrm{km}$ ); 4) geometria da estrutura (orientação, intensidade de mergulho, rugosidade e morfologia do plano); e 5) quantidade e qualidade das medidas. Este último atributo foi avaliado através de um critério de aferição de campo com base na atribuição de escores - A, B ou C decrescentes, de acordo com a qualidade de exposição das feições observadas e confiabilidade das medidas efetuadas (em especial, sentido de movimento e geometria da estrutura). Para o presente trabalho foram utilizados apenas os dados aos quais foram atribuídos escores $\mathrm{A}$ ou B. Critérios para interpretação da cronologia relativa entre as estruturas observadas e de feições na superfície das estruturas, bem como para determinação do sentido de movimento tiveram por base Tjia (1964, 1971), Petit et al. (1983), Petit (1987), Gamond (1987), Riccomini (1989), Dunne \& Hancock (1994), Caputo (1995) para as feições meso e macroscópicas principalmente, e Hancock (1985) para feições microscópicas. Os dados referentes a planos de falhas e respectivas estrias de atrito com indicação do sentido de movimento foram tratados em gabinete com aplicação de método para determinação gráfica das direções principais de esforços, como propostos em Angelier \& Mechler (1977), Angelier (1979), Angelier (1984) e Angelier (1994). Identificados os regimes de esforços e respectivos conjuntos de estruturas através de processo gráfico, foi efetuado um estudo comparativo para identificação de estruturas com diferentes sentidos de movimentação associadas a um mesmo campo de tensões através de avaliação qualitativa por análise geométrica e visual dos diagramas 
obtidos. Não foram aplicados parâmetros numéricos de quantificação de desvios-padrões, de consistência de dados, de dispersão natural de orientações e de características herdadas; os critérios utilizados em campo para controle de qualidade das medidas efetuadas foram o principal subsídio a este estudo. Os dados foram então reanalisados com aplicação de novos critérios, visando a correlação entre famílias de juntas com direções sistemáticas e regimes de esforços, o reconhecimento de sistemas conjugados e possíveis relacões com os campos de tensões identificados preliminarmente, revisão de cronologia relativa entre os conjuntos de estruturas e suas relações com cada um dos litotipos nos quais ocorrem. Posteriormente, os dados foram correlacionados ao longo de toda a área, com o intuito de avaliar a penetratividade de cada sistema ou conjunto, procurando efetuar a reconstituição de eventos e da distribuição de paleoesforços em escala regional.

Visando a correlação regional, foram estabelecidos quatro domínios estruturais, tomando as principais zonas de cisalhamento transcorrente como limites para cada domínio e prolongando hipoteticamente os limites das zonas de cisalhamento nas porções de área em que estas são recobertas pelos sedimen- tos do Subgrupo Itararé e demais coberturas. De norte para sul, estes domínios distribuem-se da seguinte forma (Fig. 2):

i) dominio Votorantim - abrange o conjunto de rochas situado na porção norte da área de estudo, limitado em grande parte (entre as localidades de Santa Helena e Piraporinha) pela Zona de Cisalhamento Transcorrente de Moreiras - ZCTM, e pela terminação da Zona de Cisalhamento Transcorrente de Pirapora - ZCTP (a oeste próximo a Salto de Pirapora).

ii) domínio Pirapora - englobando uma pequena porção de metassedimentos do Grupo São Roque e, principalmente, rochas granitóides pertencentes ao Maciço São Francisco, situados entre as zonas de cisalhamento transcorrente de Moreiras e a de Pirapora.

iii) domínio Fazendinha-Jurupará - abrange um extenso e variado conjunto de rochas compreendidas entre a Zona de Cisalhamento Transcorrente de Pirapora - ZCTP e a Zona de Cisalhamento Transcorrente de Taxaquara - ZCTT.

iv) domínio Pilar do Sul - refere-se às rochas aflorantes ao sul da Zona de Cisalhamento Transcorrente de Taxaquara.

Falhas As falhas são descontinuidades planares de dimensões geralmente decimétricas a métricas, eventualmente decamétricas a hectométricas (representáveis em mapa), que ocorrem com frequência ao longo de toda a área de estudo. Estas estruturas foram observadas principalmente nos três domínios estruturais situados ao norte da Zona de Cisalhamento de Taxaquara (Fig. 2), afetando tanto as rochas do embasamento cristalino quanto os sedimentos do Subgrupo Itararé Microfalhas são também comumente observadas em secões delgadas, deslocando o acamamento reliquiar Só ou foliações tectonometamórficas, podendo algumas dessas estruturas apresentar preenchimento mineral, principalmente por quartzo e carbonatos. Ao longo de toda a área, foram coletados 310 dados referentes a planos de falhas, 245 dos quais (cerca de $79 \%$ ) incluindo atitudes das estrias de atrito com indicação do sentido de movimento. Os diagramas de roseta apresen-

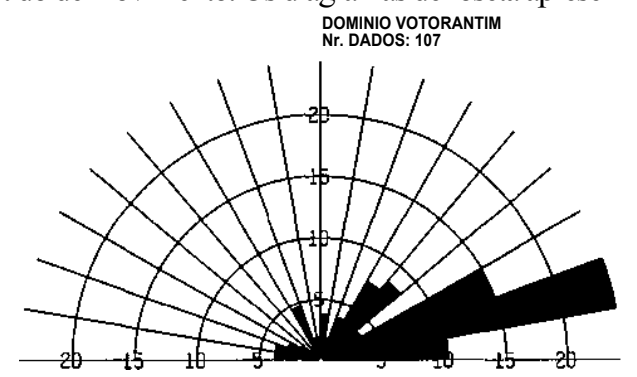

tados na figura 3 mostram a existência de três a cinco sistemas principais de direcões de falhas, que incluem: falhas de direção $\mathrm{NE}$ a ENE; falhas de direção E-W a WNW; falhas de direção N-S, falhas com direção NNE e falhas com direção NNW. Embora os dois últimos sistemas possam apenas representar variacões locais do sistema com direção N-S, a análise dos regimes de esforços e correlação entre as estruturas (incluindo geometria e relações angulares), corroboram a hipótese de sistemas individualizados. Uma análise mais pormenorizada das direções de falhas por domínio estrutural mostra o seguinte quadro: no domínio Votorantim há uma ampla predominância das estruturas com direção ENE a NE; no domínio Pirapora destacam-se estruturas nas direcões NNE, NNW e E-W a WNW; no domínio Fazendinha-Jurupará predominam as direções WNW a NW, NNW e NE. No domínio Pilar do Sul a quantidade de falhas observadas foi considerada insuficiente para o tratamento estatístico.

Juntas As famílias de juntas ocorrem de maneira generalizada ao longo da área estudada, afetando todos os litotipos, com dimensões que variam de milimétricas a decamétricas, e espacamentos centimétricos a métricos. As famílias de juntas ocorrem predominantemente na forma de juntas conjugadas de cisalhamento e juntas de extensão. Localizadamente algumas famílias de juntas apresentam relaçoes angulares que permitem o seu reconhecimento como híbridas e, mais restritamente, como sistemas ortogonais vinculados a um mesmo regime de esforços (Dunne \& Hancock 1994, Caputo 1995). Foram coletados 1013 dados de juntas em rochas do embasamento cristalino (cerca de $60 \%$ em metassedimentos associados ao Grupo São Roque) e do Subgrupo Itararé. Os diagramas de roseta da figura 4 mostram o seguinte comportamento das direções de juntas ao longo da área de estudo: no domínio Votorantim, destacam-se as estruturas com orientação NW e, secundariamente, as direções NNW e NNE; no domínio Pirapora, também são proeminentes as estruturas com direção NW, além das orientações E-W a WNW; no domínio Fazendinha-Jurupará são predominantes as estruturas nas direções WNW a NW, NNE, N-S e NNW; e, finalmente, no domínio Pilar do Sul, as direções NW e NE são as mais frequentes.

REGIMES DE ESFORCOS Com a aplicacãa de método gráfico para determinação de campos de tensões a partir de populaçõ̃es de dados de planos e estrias de falhas, de famílias de juntas, e do estabelecimento de cronologia relativa entre as estruturas observadas, foram reconhecidos seis regimes de esforços. Cada regime corresponde, muito provavelmente, a lapsos de tempo distintos, o que permite individualiza-los como eventos ou fases de deformação diferenciadas, não sendo descartada, no entanto, a hipótese de progressividade entre alguns dos eventos. Dessa forma, através das feições observadas, reco-nheceu-se o seguinte quadro para a tectônica rúptil na área estudada:

Compressão N-S a NNE-SSW (C1) O primeiro evento é deduzido pela análise do conjunto que corresponde principalmente a falhas transcorrentes sinistrais com direções preferenciais ENE (Fig. 5), subordinadamente NE. Também associadas a este regime, ocorrem DOMINIO PIRAPORA
Nr. DADOS: 102
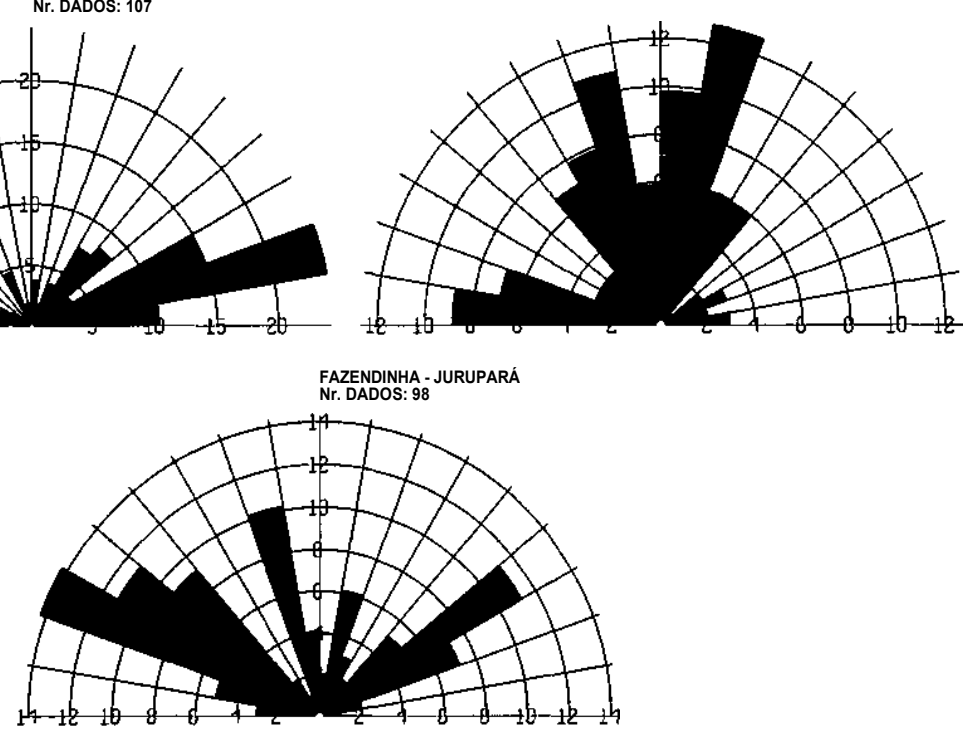

Figura 3 - Diagramas em roseta das direções de falhas em cada domínio estrutural da área estudada. Intervalos de classe de $10^{\circ}$. 
falhas de componente reversa e de componentes sinistrais com direcões NE e NNE, localmente E-W a WNW. Mais raramente, foram observadas falhas direcionais de componente destral com direcão NNW, vinculadas a este evento. Os campos de esforços obtidos forneceram um eixo de compressão máxima $\sigma_{1}$, horizontal, orientado segundo a direção N-S, com sensíveis variações para NNE-SSW.

A ampla predominância do caráter transcorrente e direcional das estruturas observadas leva a crer que o eixo de tensão principal mínima $\sigma_{3}$ (extensão), também deve ter se situado próximo à horizontal, com pequenas variações locais para posições intermediárias a subverticais. A distribuição das direções de paleoesforços obtidos para o regime de compressão $\mathrm{Cl}$ ao longo de toda a área de estudo pode ser visualizada na figura 6 .

Extensão NNW-SSE (E1) O segundo evento é representado por falhas com direções ENE a E-W e subordinadamente NE, com movimentação essencialmente normal, localmente podendo incluir componentes direcionais sinistrais (Fig. 7). Os campos de esforços obtidos indicam eixo de tensão principal mínima ( $\sigma_{3}$ (extensão) com orientação horizontal, segundo a direção NNW-SSE, e $\sigma_{1}$ predominantemente vertical havendo, entretanto, evidências ténues de que localmente ou em determinado lapso de tempo houve permuta entre posições de tensores (compressão máxima $\sigma_{1}$, suborizontal orientado aproximadamente na direção $\mathrm{E}-\mathrm{W}$, e intermediário $\sigma_{2}>$ subvertical). Esta situação parece corresponder à ocorrência de material brechado na Mina do Pastinho (localidade de Santa Helena, próximo a Votorantim), onde fragmentos de tamanhos variados de metacalcário envoltos por uma massa de calcita apresentam-se rotacionados para a direita, DOMINO VOTORANTIM
Nr.DADOS: 237

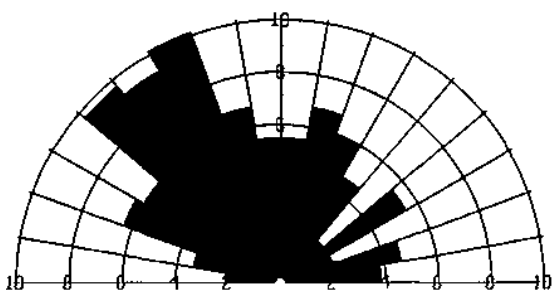

FAZENDINHA-JURUPARA

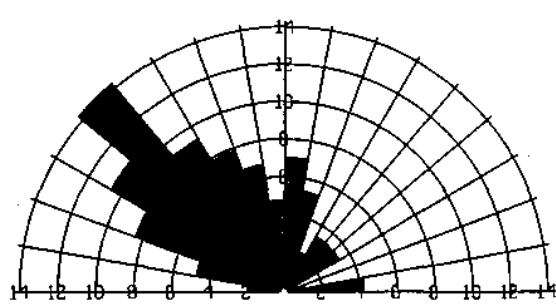

orientados aproximadamente segundo falhas irregulares de baixo ângulo na direção N-S, com caimentos para $\mathrm{E}$ ou W. Este sistema de baixo ângulo parece estar associado a falhas de movimentação normal, subverticais, de orientação ENE, subparalela à foliação tectônica no local, com um espaça-mento penetrativo da ordem de 10 a $15 \mathrm{~cm}$ e que, apesar de deslocarem o outro sistema, apresentam nítida continuidade entre os preenchimentos por calcita. O mapa esquemático da figura 8 apresenta a distribuição das direções de paleoesforços obtida para 0 regime de extensão E1 ao longo da área estudada.

Compressão NE-SW (C2) O terceiro evento compreende o conjunto constituído predominantemente por falhas transcorrentes sinistrais com direção WNW e E-W (Fig. 9A), subordinadamente ENE, e falhas direcionais de componente sinistrai, de direção WNW. Secundariamente, ocorrem estruturas de direções N-S e NNW a NW com deslocamentos destrais (Fig. 9B), componentes reversas e, mais raramente, normais. Alguns planos referentes a estas estruturas apresentam mergulhos de médio a baixo ângulo. As estruturas referentes a este evento foram geradas, e algumas podem ter sido reativadas, por um campo de esforcos com compressão máxima $\sigma_{1}$ em atitude horizontal na direção NE-SW, e eixo de tensão principal mínima $\sigma_{3}$ (extensão) na direção NW-SE em atitude similar. Localmente, $\sigma_{3}$ parece assumir posições intermediárias a subverticais implicando a presença de estruturas de componente reversa. O mapa esquemático da figura 10 apresenta as direções de paleoesforços obtidos para o regime de compressão $\mathrm{C} 2$

Compressão NW - SE (C3) Dentro da cronologia relativa estabelecida na área de estudo, este quarto conjunto compreende falhas DOMINIO PIRAPORA
Nr. DADOS: 362

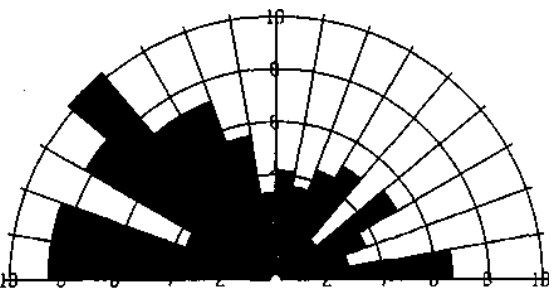

DOMINIO PILAR DO SUL
Nr.DADOS: 57

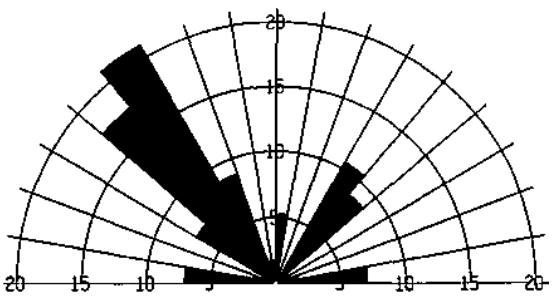

Figura 4 - Diagramas em roseta das direções de juntas em cada domínio estrutural da área estudada. Intervalos de classe de $10^{\circ}$.
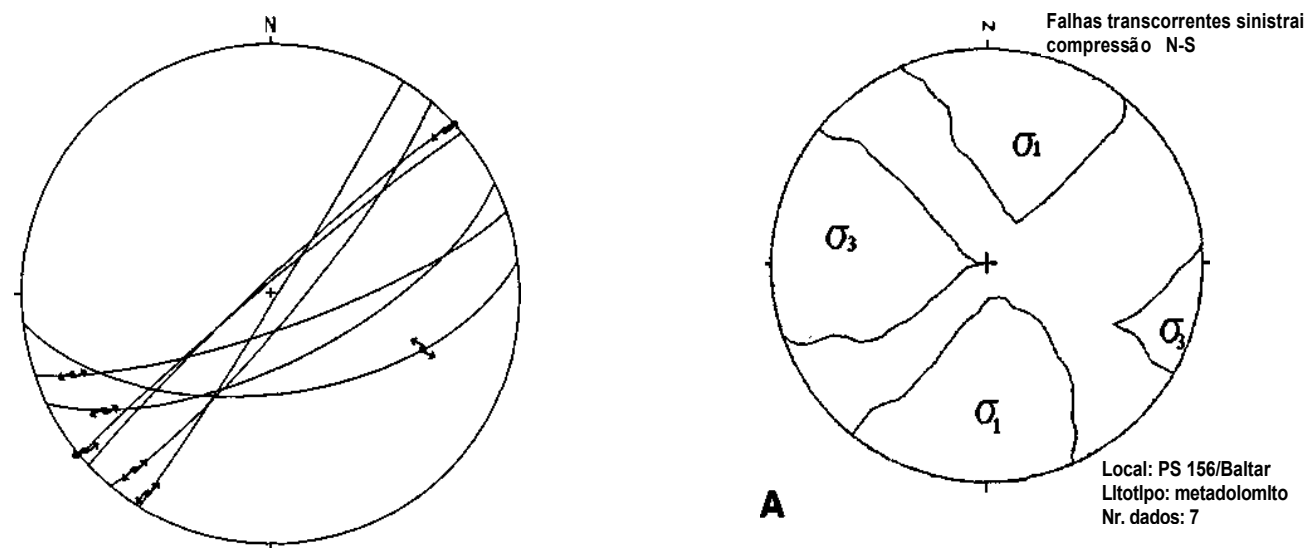

Figura 5 - Exemplo de falhas de direção NE a ENE e caráter transcorrente sinistral associadas ao regime de compressão C1, domínio Votorantim, metadolomitos associados ao Grupo São Roque, local PS-156. Lado esquerdo: projeção ciclográfica, diagrama Schmidt-Lambert, hemisfério inferior, onde os círculos máximos representam planos de falhas, os pontos e setas representam os pólos de estrias e o sentido de movimento respectivamente. Lado direito: direções de paleoesforços obtidas por método gráfico (Angelier \& Mechler 1977). Intervalos de classe: O e 99,8 $\%$. Isolinhas definem os campos com maior probabilidade de conter os eixos de tensão máxima, $\sigma_{1}$, e mínima, $\sigma_{3}$. 


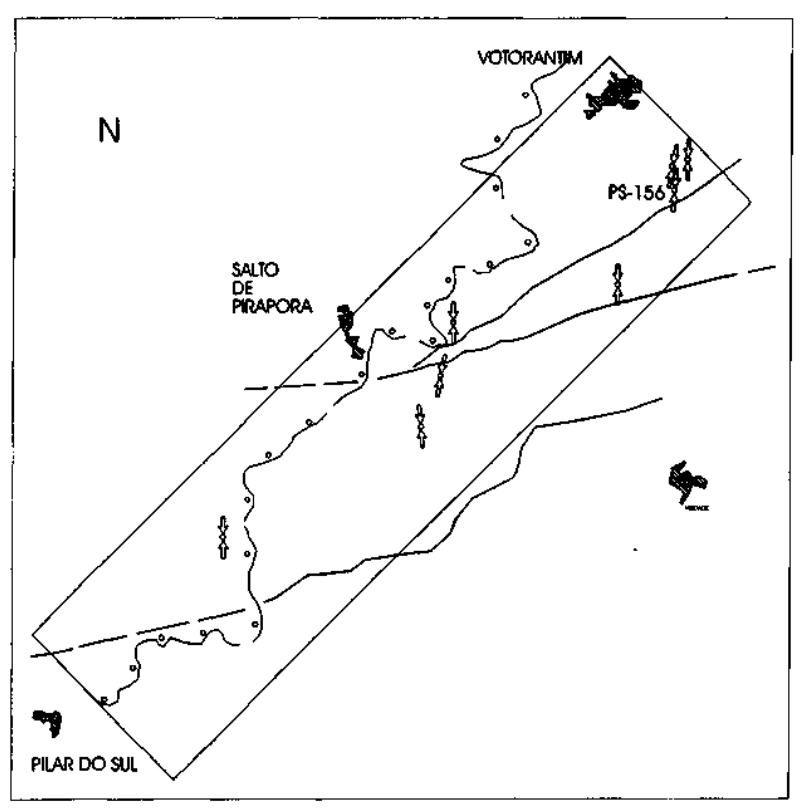

Figura 6 - Mapa esquemático mostrando a distribuição das direções principais de paleoesforços relacionados ao regime de compressão Cl na região entre Pilar do Sul e Votorantim. (Denominações e limites dos domínios estruturais encontram-se na figura 2).

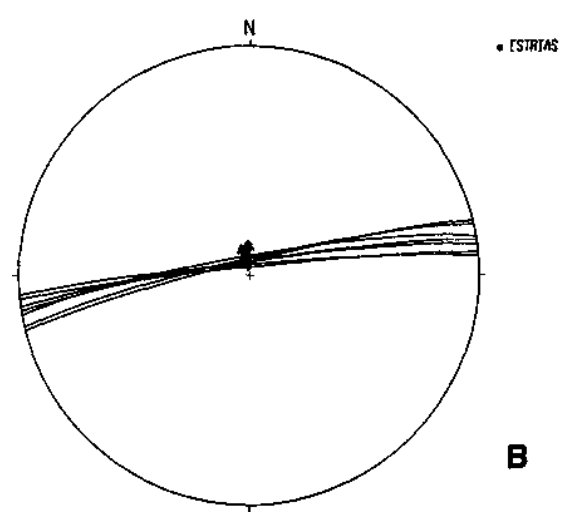

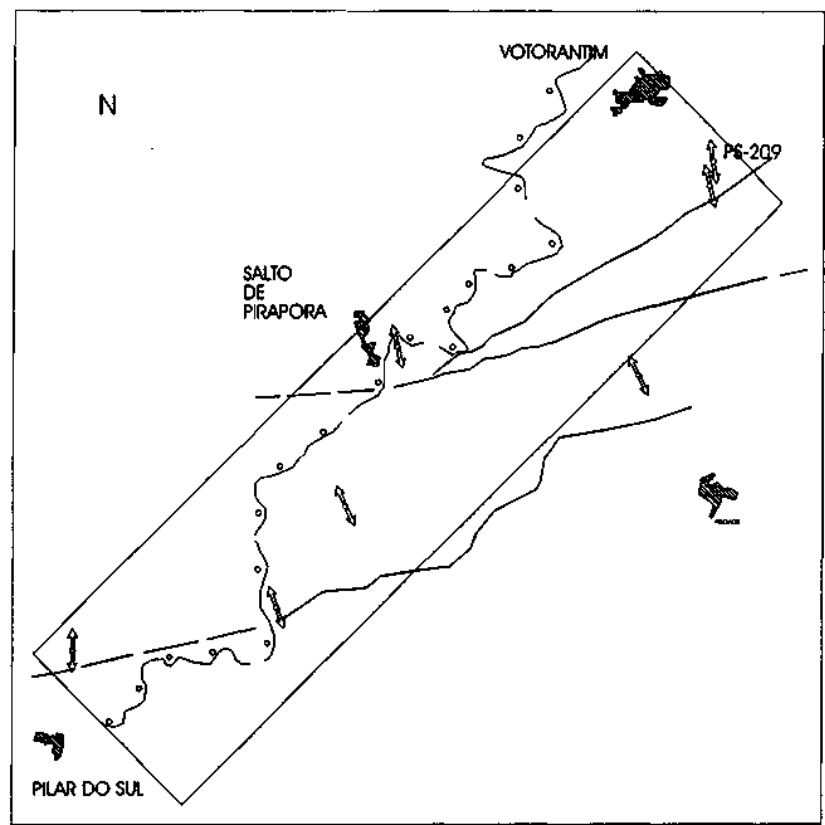

Figura 8 - Mapa esquemático mostrando a distribuição das direções principais de paleoesforços relacionados ao regime de extensão E1 na região entre Pilar do Sul e Votorantim. (Denominações e limites dos domínios estruturais encontram-se na figura 2).

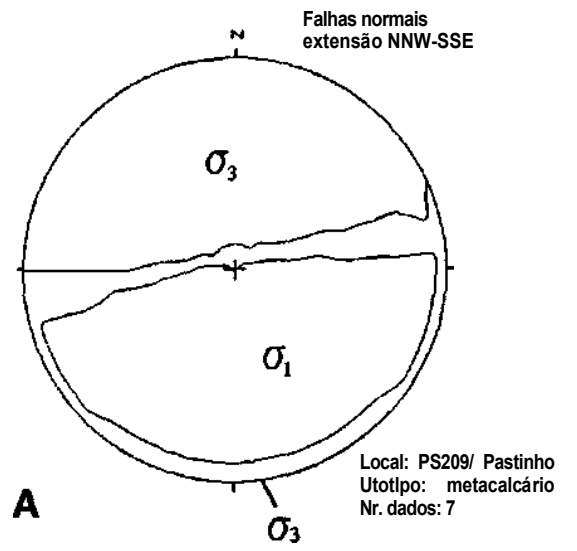

Figura 7 - Exemplo de falhas normais de direção ENE a E-W associadas ao regime de extensão E1, domínio Votorantim, metacalcários associados ao Grupo São Roque, local PS-209. Lado esquerdo: projeção ciclográfica, diagrama Schmidt-Lambert, hemisfério inferior, onde os círculos máximos representam planos de falhas, os pontos e setas representam os pólos de estrias e o sentido de movimento respectivamente. Lado direito: direções de paleoesforços obtidas por método gráfico (Angelier \& Mechler 1977). Intervalos de classe: O e 99,8\%. Isolinhas definem os campos com maior probabilidade de conter os eixos de tensão máxima $\sigma_{1}$, e mínima, $\sigma_{3}$.

de direção predominantemente ENE, subordinadamente NE e E-W, com movimentações de caráter essencialmente transcorrente destral (Fig. $11 \mathrm{~A}$ ), ou direcionais de componente destral, algumas apresentando planos com mergulhos de médio a baixo ângulo. Também estão associados a este evento falhas de direção N-S com componente reversa (Fig. 11 B), e conjugados de falha apresentando orientações entre NNE-NNW de componente sinistral e WNW-NW de componente destral (Fig $11 \mathrm{C}$ ). Mais restritamente, foram observadas famílias de juntas conjugadas de cisalhamento (Fig $11 \mathrm{C}$ ) com orientação E-W e NW que podem estar vinculadas a este evento. Grande parte das estruturas associadas a este regime de esforços foram originadas por reativações de estruturas instaladas anteriormente, como indicam os diversos planos com superposição de estrias de atrito. Os campos de tensões obtidos e a posição da bissetriz de ângulos agudos em conjugados de falha e juntas de cisalhamento indicam compressão máxima $\sigma_{1}$ em atitude horizontal, na direção NW-SE, e eixo de tensão principal mínima $\sigma_{3}$ (extensão) na direção NE-S W, que localmente pode assumir posições verticalizadas, gerando estruturas em baixo ângulo e de componentes reversas. A figura 12 apresenta mapa esquemático contendo a distribuição das direções de paleoesforços obtidos para o regime de compressão C3 ao longo da área de estudo.
Extensão WNW-ESE (E2) O quinto conjunto de estruturas compreende essencialmente falhas com movimentação normal (Fig. $13 \mathrm{~A}$ ), em alguns locais apresentando componentes sinistrals e destrais, de direções predominantemente N-S e NNE, subordinadamente NE e NNW. Destaca-se também um grande número de juntas de extensão (Fig. 13B) com direção N-S, incluindo pequenas variações na orientação para um ou outro quadrante. Os campos de tensões obtidos por método gráfico e as relações espaciais em juntas de extensão indicam o eixo de tensão principal mínima $\sigma_{3}$ (extensão) orientado suborizontalmente, segundo a direção WNW-ESE, com variações locais para WSW-ENE. O eixo de compressão máxima $\sigma_{1}$ ter-se-ia posicionado em atitude predominantemente vertical, mas podendo ocupar também posições intermediárias. A distribuição das direções de paleoesforços referentes ao regime de extensão E2 podem ser visualizadas na figura 14.

Compressão E - W (C4) O conjunto mais recente de estruturas rúpteis observado na área de estudo, compreende falhas de caráter transcorrente destral (Fig. 15A) e reverso (Fig. 15B) e, ainda, falhas direcionais de componente destral, orientadas predominantemente na direção NNE, variando em alguns locais para NNW e NE. Vinculadas 

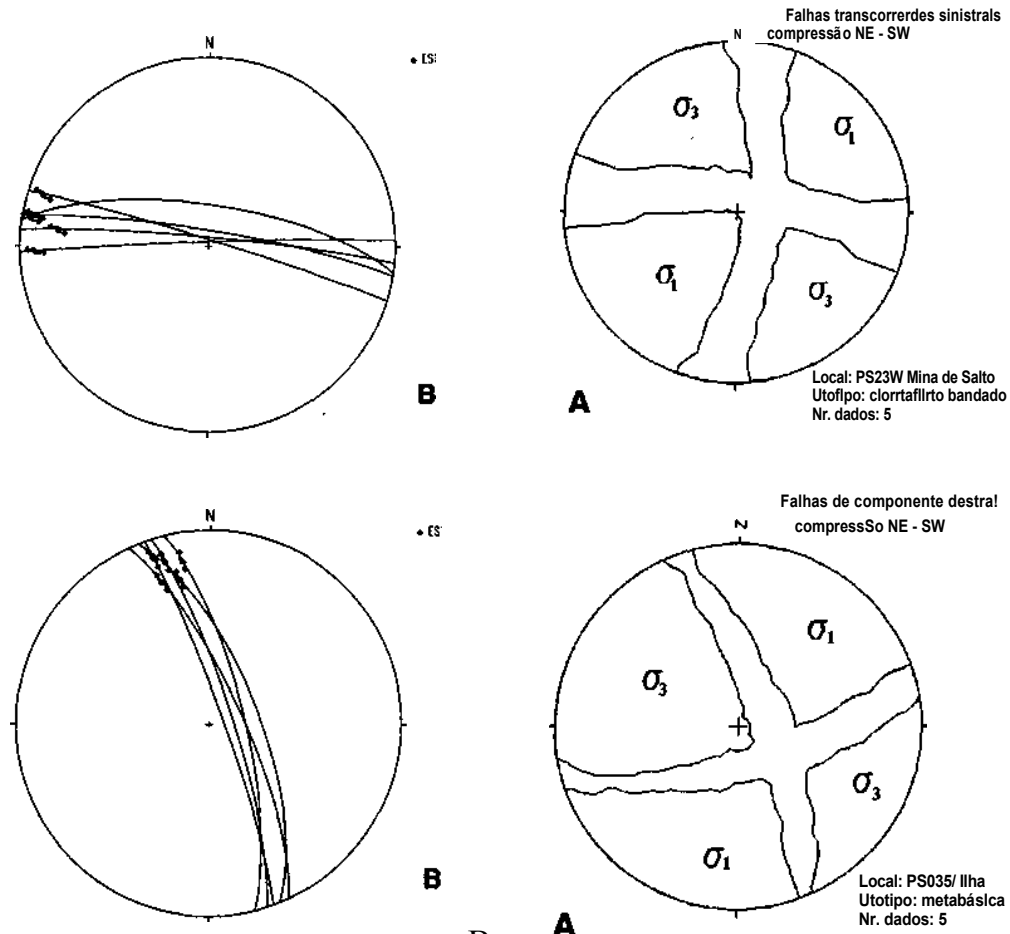

B

Figura 9 - Exemplos de falhas associadas ao regime de compressão C2. A) falhas de direção $W N W$ a E-W e caráter transcorrente sinistral afetando filitos associados ao Grupo São Roque, domínio Pirapora, local PS-230. B) falhas de direção NNW e de componente destral afetando rocha metabásica, domínio Fazendinha-Jurupará, local PS-035. Lado esquerdo de A, B: projeção ciclográfica, diagrama Schmidt-Lambert, hemisfério inferior, onde os círculos máximos representam planos de falhas, os pontos e setas representam os pólos de estrias e o sentido de movimento, respectivamente. Lado direito de A, B: direções de paleoesforços obtidas por método gráfico (Angelier \& Mechler 1977). Intervalos de classe: $O$ e 99,8\%. Isolinhas definem os campos com maior probabilidade de conter os eixos de tensão máxima $\sigma_{1}$, e mínima, $\sigma_{3}$.

a este evento, observam-se juntas de extensão com direção aproximadamente E-W e WNW, e uma grande quantidade de juntas conjugadas de cisalhamento com direcões ENE a NE e WNW a NW, cujos planos apresentam mergulhos bastante variáveis, tanto de médio a alto ângulo quanto de baixo ângulo. Estas famílias de juntas conjugadas apresentam valores de ângulo agudo entre si num intervalo entre $30^{\circ} \mathrm{e}$ $60^{\circ}$, o que pode incluir algumas estruturas na categoria de híbridas. Vale destacar que, em determinados locais, principalmente sobre rochas granitóides e metacarbonáticas maciças, foram observados sistemas de juntas subverticais em arranjo aproximadamente ortogonal (principalmente nas direções E-W e N-S, e também NNE-WNW) e com complexas relações de corte entre si, que podem corresponder a sistemas ortogonais de juntas de extensão contemporâneos (Caputo 1995), supostamente gerados durante a vigência deste regime de esforços. Os campos de tensões obtidos a partir de falhas e estrias e o posicionamento da bissetriz do ângulo agudo de juntas conjugadas de cisalhamento indicam o eixo de compressão máxima $\sigma_{1}$ orientado horizontalmente na direção E-W, com pequenas variações locais para WNW-ESE. A orientação do eixo de tensão principal mínima $a_{3}$ (extensão) parece sofrer significativas variações, passando de posições horizontalizadas, às quais estariam associadas as juntas de extensão E-W, para posições subverticais gerando estruturas de componentes reversas. Outro tipo de arranjo, implicando posições intermediárias do eixo de extensão máxima $\sigma_{3}$, ou mesmo a permuta deste com $\sigma_{2}$, pode estar representado por juntas de baixo ângulo (conjugadas ou não) com orientação E-W, nas quais se observam feicões extensionais sobre a superficie do plano (Dunne \& Hancock 1994). Tais feições correspondem a costelas (ribs) e eixos de estruturas plumosas cujas atitudes são compatíveis com a orientacão aproximadamente E-W do eixo de compressão máxima $\sigma_{1}$. A distribuição das direções dos paleoesforços pode ser visualizada na figura 16.

CONSIDERAÇÕES FINAIS A avaliação dos resultados permite afirmar que, com exceção do regime compressional de orientação N-S a NNE-SSW $(\mathrm{Cl})$, os demais regimes de esforços identificados na área de estudo correspondem aos modelos de tectônica cenozóica propostos para outras regiões situadas no estado de São Paulo (Riccomini 1989, Salvador 1994, Salvador \& Riccomini 1995). Os eventos El (extensão

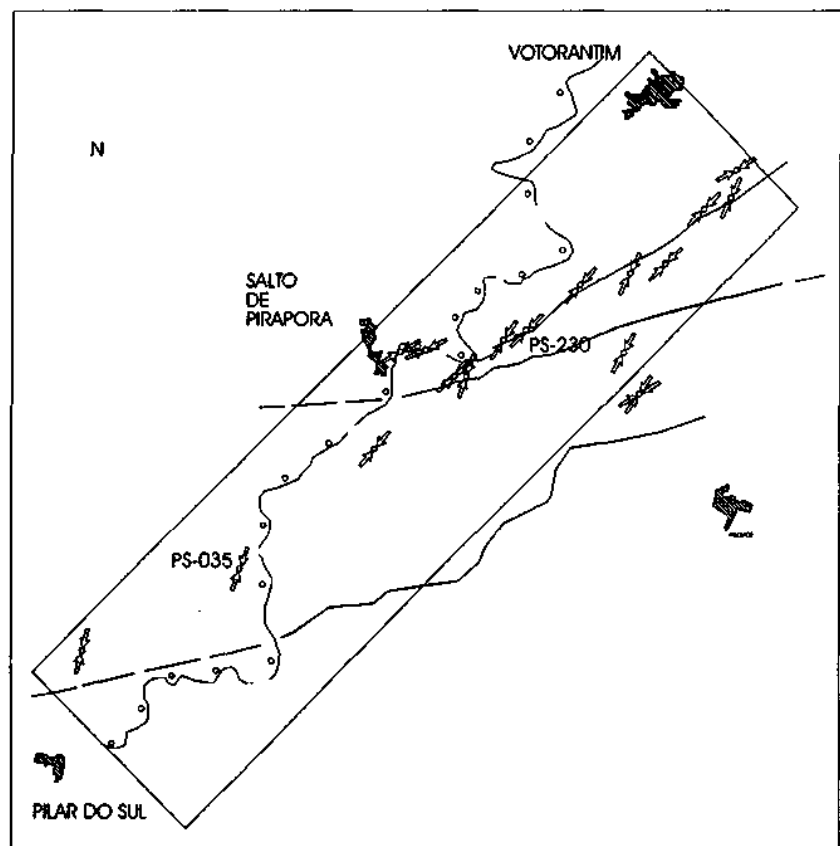

Figura 10 - Mapa esquemático mostrando a distribuição das direções principais de paleoesforços relacionados ao regime de compressão $C 2$ na região entre Pilar do Sul e Votorantim (Denominações e limites dos domínios encontram-se na figura 2).

NNW-SSE) e C2 (compressão NE-SW) relacionam-se às fases préneotectônicas definidas pelos autores citados na região do Vale do Rio Paraíba do Sul. O evento El corresponderia à fase extensional inicial, à qual Riccomini (1989) correlacionou a abertura do Rift Continental do Sudeste do Brasil, marcado nos depósitos oligocênicos da Formação Resende (Paleógeno). $\mathrm{O}$ evento compressivo $\mathrm{C} 2$ corresponde à fase transcorrente sinistral que, segundo Riccomini (1989), teria atuado 

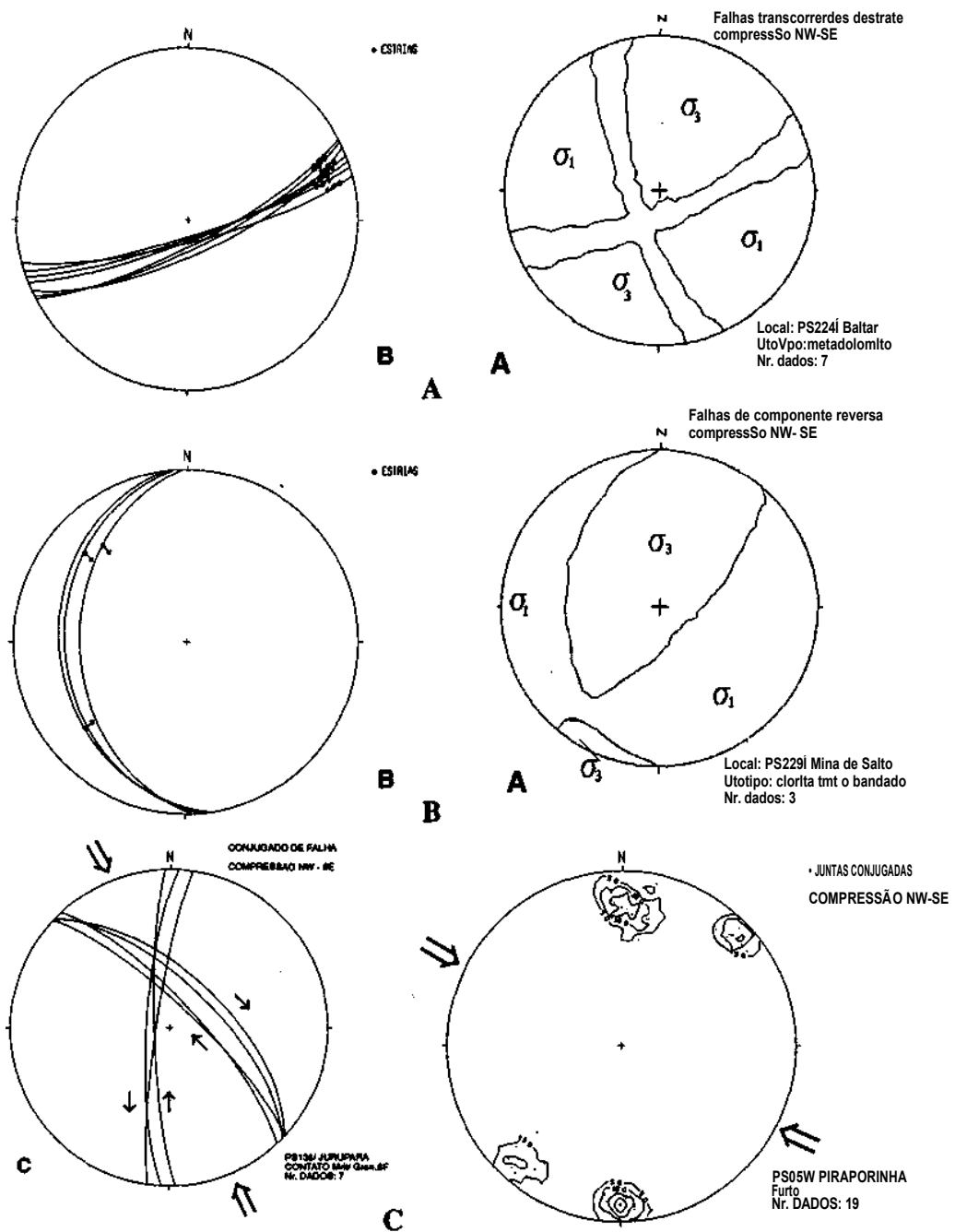

Figura 11 - Exemplos de falhas associadas ao regime de compressão C3. A) falhas de direção ENE com caráter transcorrente destral afetando metadolomitos associados ao Grupo São Roque, domínio Votorantim, local PS-224. B) falhas de direção N-S e de componente reversa afetando filitos associados ao Grupo São Roque, domínio Pirapora, local PS-229. C) lado esquerdo - planos de falha conjugados afetando o contato entre metarritmitos associados ao Grupo São Roque e rochas granitóides associadas ao Maciço São Francisco, domínio Fazendinha-Jurupará, local PS-115; lado direito -juntas conjugadas de cisalhamento afetando filitos associados ao Grupo São Roque, domínio Pirapora, local PS-059. Lado esquerdo de A, B: projeção ciclográfica, diagrama Schmidt-Lambert, hemisfério inferior, onde os círculos máximos representam planos de falhas, os pontos e setas representam os pólos de estrias e o sentido de movimento, respectivamente. Lado direito de A, B: direções de paleoesforços obtidas por método gráfico (Angelier \& Mechler 1977). Intervalos de classe: O e 99,8\%. Isolinhas definem os campos com maior probabilidade de conter os eixos de tensão máxima $\sigma_{1}$ e mínima $\sigma_{3}$. Lado esquerdo de C: projeção ciclográfica, diagrama Schmidt-Lambert hemisfério inferior, onde os círculos máximos representam planos de falhas, as setas internas representam o sentido de movimento, as setas duplas externas referem-se ao eixo de tensão máxima $\sigma_{1}$ posicionado na bissetriz do ângulo agudo entre os planos. Lado direito de C: projeção estereográfica dos pólos de planos de familias de juntas, diagrama Schmidt-Lambert, hemisfério inferior, intervalos de contorno das isolinhas $=5,10,15$ e $20 \%$, as setas duplas externas referem-se ao eixo de tensão máxima $\sigma_{1}$.

durante todo o Neógeno. Os demais eventos identificados na área estudada (C3, E2 e C4) relacionam-se às fases neotectônicas caracterizadas por Salvador (1994) e Salvador \& Riccomini (1995). O evento C3 (compressão N W-SE) corresponderia à fase transcorrente destral que, segundo os autores acima citados, afetam depósitos oligocênicos (Formação Resende), mio-pliocênicos (Formação Pindamonhangaba) e depósitos provavelmente pleistocênicos, sugerindo a atuação desse regime de esforços num intervalo de tempo compreendido entre o Pleistoceno e o início do Holoceno. O evento E2 (extensão WNWESE) corresponderia ao regime extensional E-W que, de acordo com Salvador \& Riccomini (1995), provavelmente foi instalado a partir do início do Holoceno, perdurando até $270 \pm 120$ A.P., idade referente aos depósitos de baixos terraços seccionados por falhas normais descritas por Riccomini et al. (1991). O evento C4 (compressão E-W) corresponde ao regime compressivo E-W identificado por Salvador (1994) na região denominada Alto Estrutural de Queluz (divisa entre os estados do Rio de Janeiro e São Paulo), onde famílias de juntas e falhas de componente reversa seccionam depósitos coluviais, colúvioaluviais e aluviais de idades pleistocênica e holocênica.

O modelo de evolução tectônica e sedimentação cenozóica estabelecido por Melo (1990) sugere a atuação de quatro regimes de esforços distintos distribuídos do Paleógeno ao Quaternário Superior. O esforço compressivo NE-SW assinalado pelo referido autor, compreendendo falhas de empurrão WNW-ESE e falhas direcionais sinistrais ENE-WSW, pode corresponder ao evento C2 descrito no presente trabalho. Entretanto, Melo (op.cit.) atribuiu ao Pleistoceno inferior a possível idade para atuação desses esforços, enquanto na região do Vale do Rio Paraíba do Sul, sugere-se uma atuação durante o Neógeno. Os esforços distensivos na direção WNW-ESE, caracterizados, segundo o mesmo autor por falhas normais WNW-ESE, com idade presumida do Quaternário Superior, provavelmente correlacionam-se ao evento E2 identificado no presente estudo.

Com relação ao quadro evolutivo da tectônica rúptil sugerido para a região de Campinas por Fernandes (1997), assinala-se: 


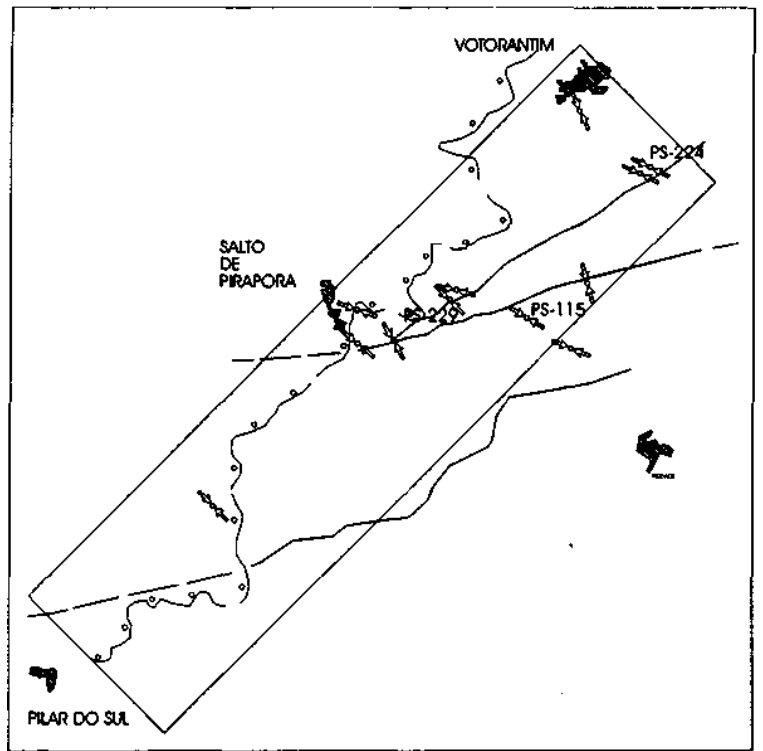

Figura 12- Mapa esquemático mostrando a distribuição das direções principais de paleoesforços relacionados ao regime de compressão $C 3$ na região entre Pilar do Sul e Votorantim (Denominações e limites dos domínios encontram-se na figura 2).

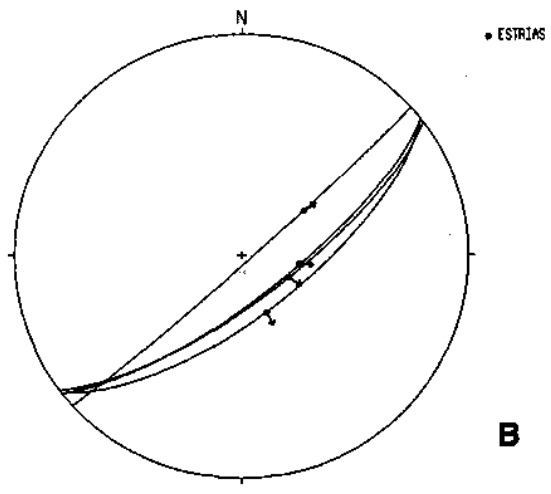

A

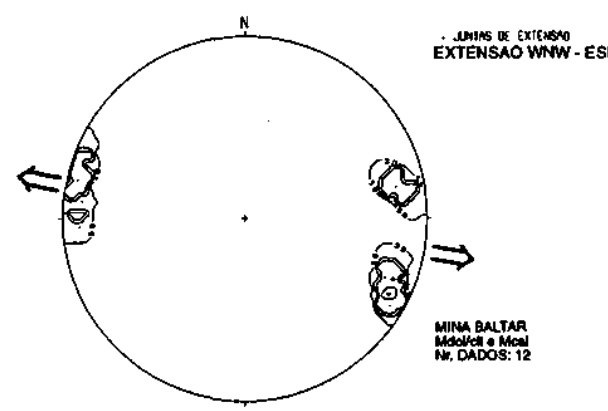

$\mathbf{B}$

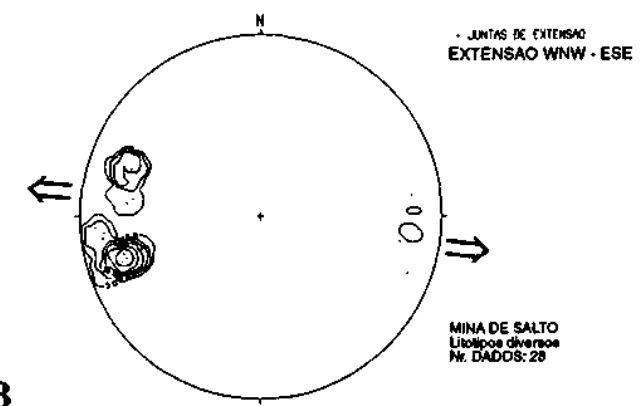

Figura 13 - Exemplos de feições de natureza rúptil associadas ao regime de extensão E2. A) Falhas normais e de componente normal predominante com direção NE, afetandofilitos associados ao Grupo São Roque, domínio Fazendinha-Jurupará, local PS-128. B) lado esquerdo -juntas de extensão afetando metadolomitos e metacalcários associados ao Grupo São Roque, domínio Votorantim, local Mina do Baltar; lado direito -juntas de extensão afetando diversos litotipos associados ao Grupo São Roque e rochas granitóides associadas ao Maciço São Francisco, domínio Pirapora, local Mina de Salto. Lado esquerdo de A: projeção ciclográfica, diagrama Schmidi-Lambert, hemisfério inferior, onde os círculos máximos representam planos de falhas, os pontos e setas representam os pólos de estrias e o sentido de movimento, respectivamente. Lado direito de A: direções de paleoesforços obtidas por método gráfico (Angelier \& Mechler 1977). Intervalos de classe: O e 99,8 \%. Isolinhas definem os campos com maior probabilidade de conter os eixos de tensão máxima, $\sigma_{1}$, e mínima, $\sigma_{3}$. Lado esquerdo e direito de B: projeção estereográfica dos pólos de planos de familias de juntas, diagrama Schmidt-Lambert, hemisfério inferior, intervalos de contorno das isolinhas $=5,10,15$ e $20 \%$; as setas duplas externas referem-se ao eixo de tensão máxima $\sigma_{1}$.

1) as feições associadas ao evento $\mathrm{C} 2$ no presente trabalho são compatíveis com o evento identificado pela referida autora como $\mathrm{T} \sigma_{1} \mathrm{NE}$, que apresenta esforços compressivos na direção NE-SW, e cujas estruturas seccionam rochas proterozóicas, o Subgrupo Itararé e a Formação Serra Geral, mas são anteriores aos depósitos considerados pela referida autora como cenozóicos;
2) o evento $\mathrm{C} 3$ identificado no presente trabalho, corresponderia ao evento $\mathrm{T} \sigma_{1} \mathrm{NW}$ de regime transcorrente, com esforços compressivos na direção NW-SE, e de idade quaternária;

3) as feições e características referentes aos demais eventos de regime transcorrente identificados pela referida autora, $\sigma_{1} \mathrm{EW}$ (pré-neotectônico), $T \sigma_{1} \mathrm{NS}$ e $\mathrm{T} \sigma_{1} \mathrm{NNE}$ (definidos como neotectônicos, e corre- 
lacionados àqueles identificados no Vale do Rio Paraíba do Sul) podem ser consideradas como parcialmente compatíveis com os eventos reconhecidos no presente trabalho. Constatam-se algumas diferenças no tipo de movimentação das feições associadas a cada um desses eventos e, conseqüentemente, na orientação dos esforços.

Os campos de esforços podem apresentar variações sob influência de fatores locais, tais como espessura crustal, carga de sedimentos acumulados e proximidade da margem continental (Assumpcão 1992, Mercier et al. 1992, Lima \& Nascimento 1994 apud Salvador \& Riccomini 1995).

Cabem alguns comentários acerca dos sistemas de estruturas rúpteis e respectivos regimes de esforcos identificados na área de estudo. $O$ evento $\mathrm{Cl}$ (compressão N-S a NNE-SSW) precede os demais; contudo, é interessante assinalar que estruturas associadas a este regime de esforços não foram observadas em sedimentos do Subgrupo Itararé, o que poderia indicar uma cronologia posterior ao Permo-Carbonífero (idade estimada para a deposição daqueles sedimentos). Todavia,

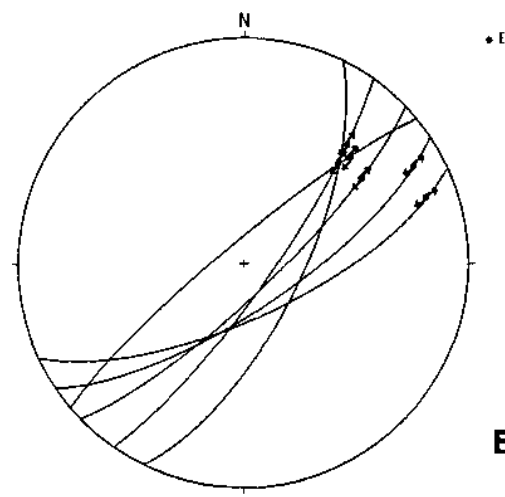

- ESIRIAS

B

$\mathbf{A}$

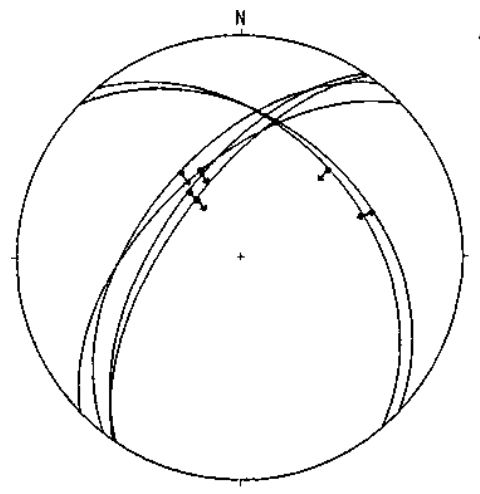

- ISTISTS

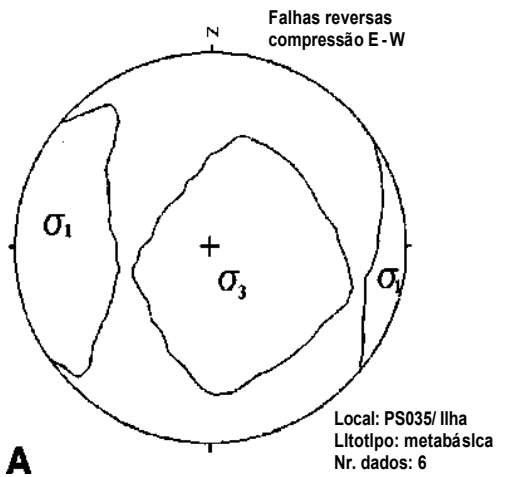

B
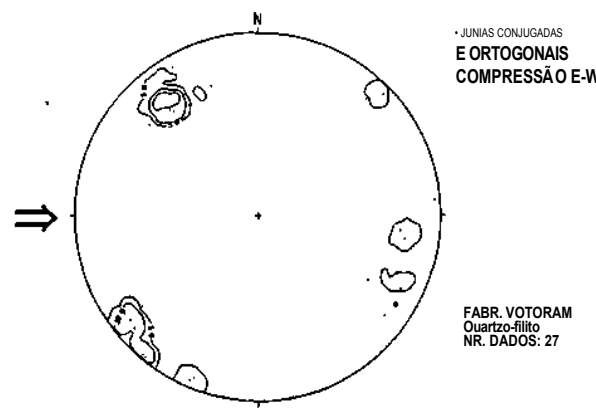

C

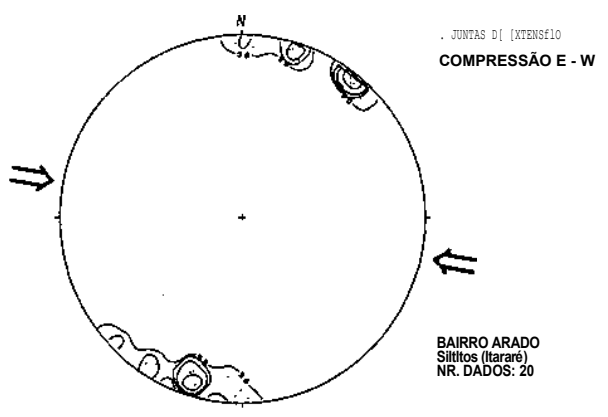

Figura 15 - Exemplos de feições de natureza rúptil associadas ao regime de compressão C4. A) falhas de direção NE a NNE com caráter transcorrente destral afetando metadolomitos associados ao Grupo São Roque, domínio Votorantim, local PS-157. B) falhas reversas de direção NNE e NNW afetando rocha metabásica, domínio Fazendinha-Jurupará, local PS-035. C) lado esquerdo -juntas conjugadas de cisalhamento afetando filitos associados ao Grupo São Roque, domínio Votorantim, local PS-219; lado direito -juntas de extensão afetando siltitos maciços associados ao Subgrupo Itararé, domínio Pirapora, local PS-191 e PS-226. Lado esquerdo de A, B: projeção ciclográfica, diagrama Schmidt-Lambert, hemisfério inferior, onde os círculos máximos representam planos de falhas, os pontos e setas representam os pólos de estrias e o sentido de movimento, respectivamente. Lado direito de A, B: direções de paleoesforços obtidas por método gráfico (Angelier \& Mechler 1977). Intervalos de classe: O e 99,8\%. Isolinhas definem os campos com maior probabilidade de conter os eixos de tensão máxima, $\sigma_{1}, e$ mínima, $\sigma_{3}$. Lado esquerdo e direito de C: projeção estereográfica dos pólos de planos de famílias de juntas, diagrama Schmidt-Lambert, hemisfério inferior, intervalos de contorno das isolinhas $=5,10,15$ e 20\%; as setas duplas externas referem-se ao eixo de tensão máxima $\sigma_{1}$. 


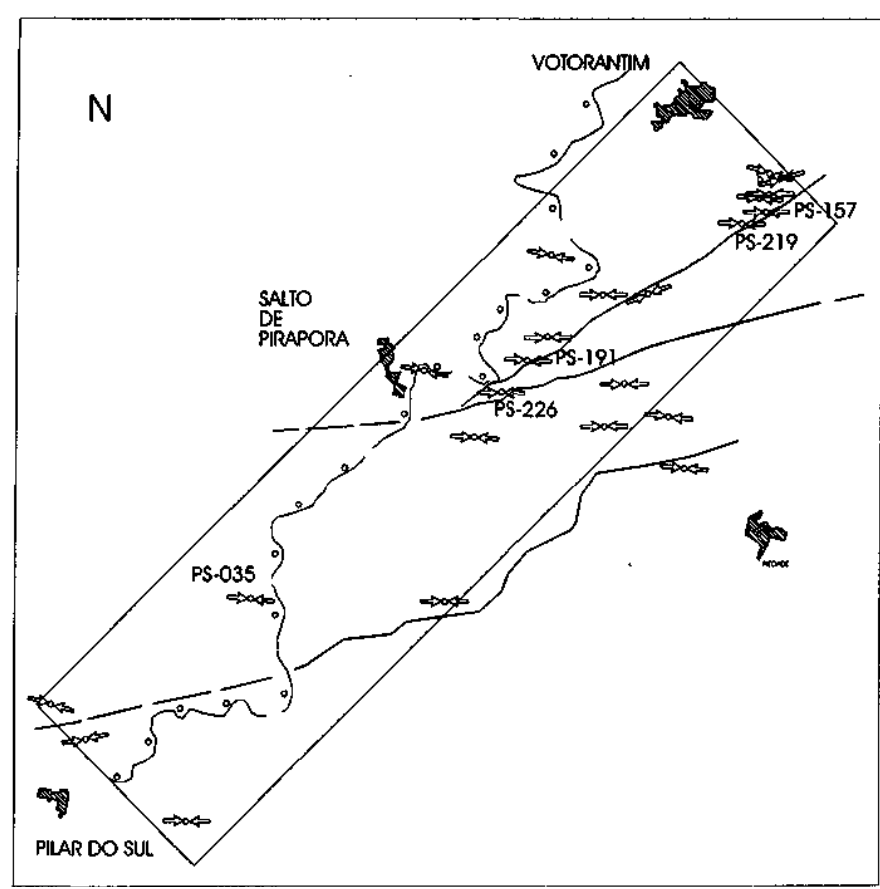

Figura 16 - Mapa esquemático mostrando a distribuição das direções principais depaleoesforços relacionados ao regime de compressão C4 na região entre Pilar do Sul e Votorantim (Denominações e limites dos domínios encontram-se na figura 2).

observações de significativa confiabilidade em falhas direcionais e de caráter transcorrente que confirmam a predominância de movimentos destrais associados a esse evento. Por outro lado, um razoável número de estruturas observadas indica a troca de posições entre os eixos de tensão principal mínima $a_{3}$ (extensão) e intermediário $\left(a_{2}\right)$.

Em geral, os rejeitos de falhas observados são centimétricos a decimétricos; entretanto, a caracterização indireta em algumas estruturas indica deslocamentos de ordem métrica a decamétrica, sendo possível, por vezes, a sua visualização em mapa ou em perfil. Nesta circunstância, as feições observadas no campo correspondem a fotolineamentos com maior expressão, e chegam a deslocar moderadamente alguns contatos entre litotipos. Estruturas vinculadas ao regime compressivo $\mathrm{C} 3$ parecem ser as responsáveis pelo deslocamento de contatos litológicos nas localidades de Piraporinha (próximo a Salto de Pirapora) e Jurupará (próximo à Cidade de Piedade, sudeste da área estudada). Nas localidades citadas, conjugados de falhas indicam que as estruturas de componente destral com orientação WNW a NW correspondem a feições sintéticas vinculadas à direção $\mathrm{R}$ do conjugado de Riedel, em um modelo com binário destral, enquanto as estruturas com orientação NNW a N-S de componentes sinistrals e normais vincular-se-iam à direção R', correspondendo a feicões antitéticas.

A ampla predominância das direções NW e E-W a WNW dentre os sistemas de juntas, observada nos diagramas de roseta da Figura 4 , aparentemente reflete a penetratividade dos dois últimos eventos de caráter rúptil (regime extensional E2 e regime compressional C4) ao longo de toda a área estudada.

Agradecimentos Ao Prof. Dr. Cláudio Riccomini pela orientacão dos trabalhos, críticas e sugestões. Ao Instituto Geológico (IG/SMA) pelo apoio financeiro e infraestrutura, à colega Amélia J. Fernandes pelo apoio nos trabalhos de campo e sugestões; ao colega Otávio C. Gandolfo pelo apoio nos trabalhos de digitalização de figuras e ilustrações; à Cristina M. Nunes, pelo apoio em todas as etapas do trabalho, incluindo digitacão de textos, tabelas e tabulacão dos dados estruturais. A CẢPES pela concessão de bolsa de estudos. Aos da RBG pela leitura crítica do presente artigo e sugestões. relatores

Angelier, J. \& Melcher, P. 1977. Sur une mélhode graphique de recherche des contraintes principies également ulilisable en tectonique et en séismologic: Ia méthode des dièdres droits. Bull.Soc.Geól.Fr., 19:1309-1318.

Angelier, J. 1979. Determinalion of the mean principal directions of stresses for a given fault population. Tectonophysics, 56: 17-26.

Angelier, J. 1984. Tectonic analysis of fault slip data sets. J Geophys. Res.. 89:5835-5848.

Angelier, J. 1994. Fault slip analysis and paleostress reconstruction. In: Hancock, P.L. (ed.) Continental Deformation. Exeter, UK, Pergamon Press Ltd. p. 53-100.

Bergmann, M. 1988. Caracterização estratigráfica e estrutural da sequência vulcano-sedimentar do Grupo São Roque, região de Pirapora do Bom Jesus(SP). São Paulo, 164p. (Dissertação de Mestrado, IG-USP).

Campos Neto, M.C.; Bergmann, M.; Siga, Jr., O; Figueiredo, M.C.H. 1990. Geologia da Folha Pilar do Sul, 1:25.000. Relatório IGUSP/PRO-MINÉRIO(inédilo), V.1, Geologia, 161p.

Caputo, R. 1995. Evolution of orthogonal sets of cocval extension joints. Terra Nova, 7:479-490.

Dunne, W.M. \& Hancock, P.L. 1994. Paleostress analysis of small-scale brittle structures. In: Hancock, P.L. (ed.). Continental Deformation. Exeter, UK, Pergamon Press Ltd. p. 101-120.

Fernandes da Silva, P.C. 1997. Ambientes de Sedimentação e Tectônica do Grupo São Roque na Região entre Pilar do Sul e Votorantim. SP. São Paulo, 127p. (Dissertação de Mestrado, IG-USP)

Fernandes, A.J. 1997. Tectônica Cenozóica na Porção Média da Bacia do Rio Piracicaba e sua Aplicação à Hidrogeologia de Meios Fraturados. São Paulo, 244p. (Tese de Doutoramento, IG-USP)

Gamond, J.F. 1987. Bridge structures as sense of displacement criteria on briltle faults. J. Struct. Geol, 9:609-620

Godoy, A.M. \& Figueiredo, M.C.H. 1991. Mapeamento faciológico e petrográfico dos Maciços Granitóides São Francisco e Pirapora (SP). In: In: Simpósio de Geologia do Sudeste, 2. São Paulo, 1991.Atas...São Paulo, SBG. p. 131-138.

Godoy, A.M. 1989. Caracterização Faciológica, Petrográftca e Geoquimica dos Maciço Sorocaba e São Francisco, SP. São Paulo, 220p. (Tese de Doutoramento, IG-USP)

Hackspacher, P.C. 1994. Tectônica Transtensiva/Transpressiva e Alojamento de Rochas Plutônicas, a exemplo da Folha Cabreúva (SP) 1:50.000. Rio Claro, 203p. (Tese de Livre Docência, IGCE-UNESP)

Hackspacher, P.C.; Godoy, A.M.; Oliveira, M.A.F. 1993. Evolução crustal do Bloco São Roque na região sudeste do Estado de São Paulo. Rev. Brás. Geoc., 23(3):260-264

Hancock, P.L. \& Engelder, T. 1989. Neotectonic joints. Geol. Soe. Am. Bull, 101:1197-1208.

Hancock, P.L. 1985. Brittle microtectonics: principies and practicc. J. Struct. Geol. 7:437-457.

Hasui, Y. 1973. Tectônica da área das folhas S.Roque e Pilar do Sul. São Paulo, 190p. (Tese de Livre Docência -IG/USP)

Hasui, Y. 1975. Geologia da Folha São Roque-Boi. IG/USP . 6:157-183.

Hasui, Y.; Penalva, F.; Hennies, W.T. 1969. Geologia do Grupo São Roque. In: Congresso Brasileiro de Geologia, 23, Salvador, 1969. Anais...Salvador, SBG, v.1, p.101-134.

Instituto de Pesquisas Tecnológicas. 1981. Mapa Geomorfológico do Estado de São Paulo, Esc. 1:1.000.000. São Paulo, IPT. 2v.

Instituto Geológico/SMA - 1990 - Mapeamento Geológico da Folha Salto de PiraporafSP), Escala 1:50.000. Relatório Técnico IG/SMA/SP (inédito), v. 1,76p.

Julinai, C.; Beljavskis, P.; Schörscher, H.D. 1986. Petrogênese do vulcanismo e aspectos metalogenéticos associados: Grupo Serra de Ilabcraba na região de São Roque(SP). In: Congresso Brasileiro de Geologia, 34, Goiânia, 1986. Anais...Goiânia, SBG, v.2, p.730-750.

\section{Referências}

Martonne, E. de. 1943. Problemas morfológicos do Brasil tropical Atlântico. Rev. Brás. Geogr. Sãp Paulo, 4:523-550.

Massoli, M. 1991. Relação entre o embasamento cristalino e os sedimentos basais do Subgrupo Itararé na região de Sorocaba - Salto de Pirapora, SP. São Paulo, 94p. (Dissertação de Mestrado, IG-USP)

Melo, M.S. 1990. A Formação Pariqüera-Açu e Depósitos Relacionados: Sedimentação, Tectônica e Geomorfogênese. São Paulo, 210p. (Dissertação de Mestrado, IG-USP)

Melo, M. S.; Riccomini, C.; Almeida, F.F.M.; Hasui, Y. 1985. Sedimentação e teclônica da Bacia de Resende - RJ. An. Acad. Brás. Ci, 57:467-479.

Modenesi, M.C. 1974. Níveis de erosão em formações superficiais na região de Itu - Salto. Rev. Brás. Geoc., 4(4):228-236.

Oliveira, M.A.F.; Godoy, A.M.; Zanardo, A.; Arthur, A.C.; Hackspacher, P.C.; Morales, N. 1992 Geologia da Folha São Roque(SP). In: CONGR.BRAS.GEOL., 37, São Paulo, 1992. Boi Res. Exp...São Paulo, SBG, v.2, p.126-127.

Pellogia, A.U.G. \& Bermann, M. 1992. Aspectos da geologia do Subgrupo Itararé na região de Pilar do Sul. In: Congresso Brasileiro de Geologia, 37, São Paulo, 1992. Bol,Res.Exp...São Paulo, SBG, v.2, p.522-523

Petit J.P. 1987. Criteria for the sense of movement on faull surfaces in brittle rocks. J.Struct. Geol., 9(5):597-608.

Petit, J.P.; Prousl, F.; Tapponier, P. 1983. Cri teres de sens de mou vement sur Ies mirroirs de failles en roches non calcaires. Bull. Soe. géol. Fr., 7 Ser. XXV, p. 589-608.

Pires, F.A. \& Pelri, S. 1991. O Subgrupo Itararé (Permocarbonífero) na região do médio Tietê, Estado de São Paulo. In: Simpósio de Geologia do Sudeste, ,2. São Paulo, 1991. Atas...São Paulo, SBG. p. 391-396.

Riccomini, C. 1989. O Rift Continental do Sudeste do Brasil. São Paulo, 256p. (Tese de Doutoramento, IG-USP).

Riccomini, C.; Appi, C.J.; Freitas, E.L.; Arai, M. 1987. Tectônica e sedimentação do Sistema de Rifla Continentais da Serra do Mar (bacias de Volta Redonda, Resende, Taubaté e São Paulo). In: Simpósio de Geologia, RJ-ES., 1, Rio de Janeiro. Anais... Rio de Janeiro, SBG, p.253-298.

Riccomini, C.; Peloggia, A.U.G.; Saloni, J.C.L.; Kohnke, M.W.; Figueira, R.M. 1989. Neotectonic activily in the Serra do Mar rifl system (Southcastern Brazil). J. South Am. Eart/iSd., 2:191-197.

Riccomini.C.: Turq, B.: Suguio, K. 1991. The record of continental sedimentation in Southeastern Brasil during the last millennium: paleoscismicity, the little ice age and man. An. Acad. Brás. Ci., 63:90.

Salvador, E.D. \& Riccomini, C. 1995. Neotectônica da Região do Alto Estrutural de Queluz (SP-RJ, Brasil). Rev. Brás. Geoc., 25(3): 151-164.

Salvador, E.D. 1994. Análise Neotectônica da Região do Vale do Paraíba compreendida entre Cruzeiro (SP) e Itatiaia (RJ). São Paulo, 129p. (Dissertação de Mestrado, IG-USP).

Stein, D.P. - 1984 - Esboço da evolução geológica pré-cambriana da Folha Pilar do Sul, SP (SF-23-Y-C-IV-4). São Paulo, 148p. (Dissertação de Mestrado, IG-USP).

Tjia, HD. 1964. Sliekensides and fault movements. Geol. Soe. Am Bull, 75:683-685.

Tjia, H.D. 1971. Fault movement, reoriented stress field and subsidiary structures. Pacific Geol., 5:49-70.

Manuscrito A-980

Recebido em 11 de maio de 1998 Revisão do autor em 28 de agosto de 1998 Revisão aceita em 05 de setembro de 1998 